\title{
Front Matter: Volume 8415
}

, "Front Matter: Volume 8415," Proc. SPIE 8415, 6th International Symposium on Advanced Optical Manufacturing and Testing Technologies: Large Mirrors and Telescopes, 841501 (15 October 2012); doi: 10.1117/12.2010437

EDent: 6th International Symposium on Advanced Optical Manufacturing and Testing Technologies (AOMATT 2012), 2012, Xiamen, China 


\title{
6th International Symposium on Advanced Optical Manufacturing and Testing Technologies \\ Large Mirrors and Telescopes
}

\author{
Wenhan Jiang \\ Myung K. Cho \\ Fan Wu \\ Editors
}

\section{6-29 April 2010}

Xiamen, China

Sponsored by

COS-The Chinese Optical Society (China)

IOE-The Institute of Optics and Electronics, CAS (China)

Technical Cosponsor

SPIE

Supporting Organizations

Ministry of Science and Technology of China (China)

Chinese Academy of Sciences (China)

National Natural Science Foundation of China (China)

Published by

SPIE 
The papers included in this volume were part of the technical conference cited on the cover and title page. Papers were selected and subject to review by the editors and conference program committee. Some conference presentations may not be available for publication. The papers published in these proceedings reflect the work and thoughts of the authors and are published herein as submitted. The publisher is not responsible for the validity of the information or for any outcomes resulting from reliance thereon.

Please use the following format to cite material from this book:

Author(s), "Title of Paper," in 6th International Symposium on Advanced Optical Manufacturing and Testing Technologies: Large Mirrors and Telescopes, edited by Wenhan Jiang, Myung K. Cho, Fan Wu, Proceedings of SPIE Vol. 8415 (SPIE, Bellingham, WA, 2012) Article CID Number.

ISSN: 0277-786X

ISBN: 9780819490971

Published by

SPIE

P.O. Box 10, Bellingham, Washington 98227-0010 USA

Telephone +1 3606763290 (Pacific Time) · Fax +1 3606471445

SPIE.org

Copyright (C) 2012, Society of Photo-Optical Instrumentation Engineers.

Copying of material in this book for internal or personal use, or for the internal or personal use of specific clients, beyond the fair use provisions granted by the U.S. Copyright Law is authorized by SPIE subject to payment of copying fees. The Transactional Reporting Service base fee for this volume is $\$ 18.00$ per article (or portion thereof), which should be paid directly to the Copyright Clearance Center (CCC), 222 Rosewood Drive, Danvers, MA 01923. Payment may also be made electronically through CCC Online at copyright.com. Other copying for republication, resale, advertising or promotion, or any form of systematic or multiple reproduction of any material in this book is prohibited except with permission in writing from the publisher. The CCC fee code is 0277-786X/12/\$18.00.

Printed in the United States of America.

Publication of record for individual papers is online in the SPIE Digital Library.

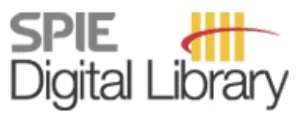

SPIEDigitalLibrary.org

Paper Numbering: Proceedings of SPIE follow an e-First publication model, with papers published first online and then in print and on CD-ROM. Papers are published as they are submitted and meet publication criteria. A unique, consistent, permanent citation identifier (CID) number is assigned to each article at the time of the first publication. Utilization of CIDs allows articles to be fully citable as soon as they are published online, and connects the same identifier to all online, print, and electronic versions of the publication. SPIE uses a six-digit CID article numbering system in which:

- The first four digits correspond to the SPIE volume number.

- The last two digits indicate publication order within the volume using a Base 36 numbering

system employing both numerals and letters. These two-number sets start with 00, 01, 02, 03, 04, $05,06,07,08,09,0 A, 0 B \ldots$. 0Z, followed by 10-1Z, 20-2Z, etc.

The CID Number appears on each page of the manuscript. The complete citation is used on the first page, and an abbreviated version on subsequent pages. Numbers in the index correspond to the last two digits of the six-digit CID Number. 


\title{
Contents
}

\author{
ix Symposium Committee \\ xi Introduction \\ xiii AOMATT 2012 Sponsors
}

SESSION 1-1

841502 Thermodynamics research on optical system based on finite element method [8415-11] H. Y. Ming, M. C. Hui, Beijing Institute of Technology (China)

841503 Analysis led design and optimization for large aperture mirror [8415-9] H. Hu, Changchun Institute of Optics, Fine Mechanics and Physics (China) and Key Lab. of Optical System Advanced Manufacturing Technology (China); Y. Guan, Changchun Univ. of Technology (China); L. Zheng, Changchun Institute of Optics, Fine Mechanics and Physics (China) and Key Lab. of Optical System Advanced Manufacturing Technology (China)

841504 Comparison of optimization algorithms for adaptive optics system without a wavefront sensor [8415-22]

Y. Liu, J. Ma, B. Li, Y. Hu, J. Chu, Univ. of Science and Technology of China (China)

841505 Parametric definition for the $\mathrm{CGH}$ patterns and error analysis in interferometric measurements [8415-400]

P. Zhou, W. Cai, C. Zhao, J. H. Burge, College of Optical Sciences, The Univ. of Arizona (United States)

841506 Research on eliminating high-order spectrum in broadband miniature spectrometer system [8415-30]

K. Liu, F. Yu, Zhejiang Univ. (China)

SESSION 1-2

841507 Large field-of-view configurations for large-telescope adaptive optics systems: advantages and tradeoffs [8415-55]

X. Zhang, Max-Planck-Institut für Astronomie (Germany), Institute of Optics and Electronics (China), Key Lab. of Adaptive Optics (China), and Graduate School of the Chinese Academy of Sciences (China); T. M. Herbst, Max-Planck-Institut für Astronomie (Germany); C. Rao, Institute of Optics and Electronics (China); P. Bizenberger, A. R. Conrad, MaxPlanck-Institut für Astronomie (Germany); C. Arcidiacono, INAF - Osservatorio Astronomico di Bologna (Italy) and INAF - Arcetri Astrophysical Observatory (Italy); W. Gaessler, MaxPlanck-Institut für Astronomie (Germany); R. Ragazzoni, INAF - Osservatorio Astronomico di Padova (Italy); T. Bertram, Max-Planck-Institut für Astronomie (Germany) 
841508 Integrated modeling and optical jitter analysis of a high resolution space camera [8415-46] B. Zhang, X. Wang, Y. Hu, Beijing Institute of Space Mechanics and Electricity (China)

841509 Measurements of the backscattering of ultrasmooth mirrors [8415-500]

J. Wang, K. Wang, Aviation Industry Corp. of China (China)

8415 OA Dwell time calculation for computer controlled large tool [8415-64]

B. Fan, Institute of Optics and Electronics (China) and The Univ. of Arizona (United States);

J. H. Burge, H. Martin, The Univ. of Arizona (United States); Z. Zeng, X. Li, J. Zhou, Institute of Optics and Electronics (China)

8415 OB Development status of the prototype of the GMT fast steering mirror [8415-74]

Y.-S. Kim, J. H. Koh, I. Chung, Korea Astronomy and Space Science Institute (Korea,

Republic of); M. Cho, National Optical Astronomy Observatory (United States); H.-S. Yang, Korea Research Institute of Standards and Science (Korea, Republic of); H.-S. Kim, Institute for Advanced Engineering (Korea, Republic of); H.-S. Ahn, Gwangju Institute of Science and Technology (Korea, Republic of); I. Han, J. Kyeong, M.-Y. Chun, B.-G. Park, Korea Astronomy and Space Science Institute (Korea, Republic of)

$84150 \mathrm{C}$ Error budgeting as applied to the design of the International X-Ray Observatory Mandrel Measuring Machine [8415-148]

D. C. Thompson, D. H. Youden, Praecis, Inc. (United States)

POSTER SESSION

8415 OD Design and optimization of push-pull-shear lateral support of thin meniscus mirror [8415-1] F. Chen, Changchun Institute of Optics, Fine Mechanics and Physics (China) and Graduate Univ. of the Chinese Academy of Sciences (China); J. Zhang, X. Wu, Changchun Institute of Optics, Fine Mechanics and Physics (China); L. Fan, H. Zhao, Changchun Institute of Optics, Fine Mechanics and Physics (China) and Graduate Univ. of the Chinese Academy of Sciences (China)

8415 OE A new method that indicates the peak stress of random vibration response [8415-54] Y. Yan, P. Xie, Z. Xu, G. Jin, Changchun Institute of Optics, Fine Mechanics and Physics (China)

8415 OF Compute simulation of oscillation characteristic on plane matrix multiple coherence based on phase modulation [8415-43]

P. Wang, J. Chai, New Star Research Institute of Applied Technology (China)

$84150 G \quad$ Alignment technology of large telescope main optical system [8415-31]

Q. XU, Institute of Optics and Electronics (China) and Graduate School of the Chinese Academy of Sciences (China); F. Wu, M. Zhang, Institute of Optics and Electronics (China); B. Wang, Institute of Optics and Electronics (China) and Graduate School of the Chinese Academy of Sciences (China)

$8415 \mathrm{OH}$ Designing of supports for a $1.2 \mathrm{~m}$ active thin mirror [8415-10]

P. Yao, Institute of Optics and Electronics (China), Key Lab. on Adaptive Optics (China), and Graduate School of the Chinese Academy of Sciences (China); X. Zhang, Y. Zhang, Institute of Optics and Electronics (China) and Key Lab. on Adaptive Optics (China) 
8415 ol A novel large scale focal plane telescope using focal plane pointing method [8415-20] J. Lin, Shanghai Institute of Technical Physics (China) and Graduate School of the Chinese Academy of Sciences (China); L. Sun, Shanghai Institute of Technical Physics (China); C. Yong, Shanghai Institute of Technical Physics (China) and Graduate School of the Chinese Academy of Sciences (China); L. Yang, F. Chen, Shanghai Institute of Technical Physics (China)

$84150 \mathrm{~J}$ Development of defects detection in gluing glass [8415-19] Z. Wu, Institute of Optics and Electronics (China) and Graduate Univ. of the Chinese Academy of Sciences (China); W. Yang, T. Fan, Institute of Optics and Electronics (China)

$84150 \mathrm{~K}$ Measurement of an off-axis parabolic mirror using coordinates measurement machine and swing arm profilometer during the grinding process [8415-45]

H. Jing, C. Lin, B. Fan, L. Kuang, S. WU, F. WU, T. Fan, Institute of Optics and Electronics (China)

$8415 \mathrm{OL}$ Thermal analysis of a $\mathbf{4 m}$ honeycomb telescope primary mirror [8415-14] J. Zhang, Institute of Optics and Electronics (China), Key Lab. on Adaptive Optics (China), and Graduate School of the Chinese Academy of Sciences (China); H. Xian, Institute of Optics and Electronics (China) and Key Lab. on Adaptive Optics (China)

8415 OM Design of large aperture focal plane shutter [8415-18]

J. Hu, Institute of Optics and Electronics (China) and Graduate Univ. of the Chinese Academy of Sciences (China); W. Ma, J. Huang, Institute of Optics and Electronics (China)

$8415 \mathrm{ON}$ The design for off-axis multimirror optical system with large field and small $\mathbf{F}$ number using coaxial assembly of two mirrors [8415-60]

H. Liu, S. Yan, Air Force Radar Academy (China); Y. Pei, Shanghai Institute of Technical Physics (China); L. Hu, S. Xu, Air Force Radar Academy (China)

841500 Restoration of observed image with an unknown space-variant blur from wide-field telescope [8415-15]

C. He, Institute of Optics and Electronics (China) and Graduate School of the Chinese Academy of Sciences (China); H. Wei, M. Shen, Institute of Optics and Electronics (China)

$8415 \mathrm{OP}$

Thin-film thickness measurement method based on the reflection interference spectrum [8415-5]

L. N. Jiang, G. Feng, Univ. of Science and Technology Liaoning (China); Z. Shu, East Port Technology Development Co., Ltd. (China)

$84150 Q \quad$ LINC-NIRVANA: cryogenic optics for diffraction limited beam combination [8415-56] P. Bizenberger, H. Baumeister, T. Herbst, X. Zhang, Max-Planck-Institut für Astronomie (Germany)

8415 OR Finite element analysis of lightweight active primary mirror [8415-17] W. X. Lu, Institute of Optics and Electronics (China), Key Lab. on Adaptive Optics (China), and Graduate School of the Chinese Academy of Sciences (China); C. L. Guan, C. H. Rao, Institute of Optics and Electronics (China) and Key Lab. on Adaptive Optics (China)

8415 OS Design of automatic leveling and centering system of theodolite [8415-25]

C. Liu, Z.-X. He, X. Huang, Y. Zhan, Xi'an Research Institute of High Technology (China) 
8415 ОT Integrated optimum design for a honeycomb mirror [8415-39]

J. Tang, S. Wang, J. Zhang, Institute of Optics and Electronics (China), Key Lab. on

Adaptive Optics (China), and Graduate School of the Chinese Academy of Sciences

(China); H. Xian, Institute of Optics and Electronics (China) and Key Lab. on Adaptive Optics (China)

8415 OU Herschel Space Observatory Telescope characterization with Hartmann wavefront sensor [8415-38]

G. Dovillaire, Imagine Optic SA (France); Y. Wang, Imagine Optic China (China); R. Toth, Imagine Optic SA (France); R. Porcar-Guézénec, COSINGO-Imagine Optic Spain SL (Spain)

8415 OV Real time controller for 37-element low-order solar adaptive optics system at $1 \mathrm{~m}$ new vacuum solar telescope [8415-58]

L. Zhu, N. Gu, S. Chen, Key Lab. on Adaptive Optics (China) and Institute of Optics and Electronics (China); L. Zhang, Key Lab. on Adaptive Optics (China), Institute of Optics and Electronics (China), and Graduate School of the Chinese Academy of Sciences (China); X. Wang, X. Rao, M. Li, C. Rao, Key Lab. on Adaptive Optics (China) and Institute of Optics and Electronics (China)

8415 OW Simulation result of multi-conjugate adaptive optics system based on minimum mean square error approach wavefront reconstruction [8415-36]

L. Zhang, Institute of Optics and Electronics (China), Key Lab. on Adaptive Optics (China), and Graduate School of the Chinese Academy of Sciences (China); C. Rao, Institute of Optics and Electronics (China) and Key Lab. on Adaptive Optics (China)

$84150 X$ Adaptive filter and linear quadratic Gaussian/loop transfer recovery compensator combination control of a non-linear tip-tilt mirror [8415-12]

Y. Guo, Institute of Optics and Electronics (China), Key Lab. on Adaptive Optics (China), and Graduate Univ. of the Chinese Academy of Sciences (China); X. Ma, C. Rao, Institute of Optics and Electronics (China) and Key Lab. on Adaptive Optics (China)

8415 OY Optimization of yoke of a large telescope for mechanical reliability [8415-23]

K. He, Institute of Optics and Electronics (China) and Graduate Univ. of the Chinese Academy of Sciences (China); W. Ma, J. Huang, Institute of Optics and Electronics (China)

$84150 Z$ Optical design of Cassegrain system with wide field of view for spaceborne remote sensing application [8415-51]

X. Yang, A. Geng, Huazhong Institute of Electro-Optics (China)

841510 Design and analysis of structure of large aperture three-mirror off-axis optical system [8415-27]

K. Wang, J. Dong, W. Li, Q. Guo, Y. Li, W. Zhao, X. Cao, H. Wang, Changchun Institute of Optics, Fine Mechanics and Physics (China)

841511 Design and analysis on a kind of primary reflector support structure based on thermal compensation principle [8415-4]

C. Yan, Institute of Optics and Electronics (China) and Graduate School of the Chinese

Academy of Sciences (China); W. Liu, Q. WU, Institute of Optics and Electronics (China) 
841512 Thermal analysis of a $1.8 \mathrm{~m}$ solar telescope mechanical structure [8415-26]

C. Li, Institute of Optics and Electronics (China), Key Lab. on Adaptive Optics (China), and Graduate School of the Chinese Academy of Sciences (China); H. Xian, Institute of Optics and Electronics (China) and Key Lab. on Adaptive Optics (China); J. Zhang, Institute of Optics and Electronics (China), Key Lab. on Adaptive Optics (China), and Graduate School of the Chinese Academy of Sciences (China)

841513 Applications of liquid crystal adaptive optics for larger aperture telescope [8415-6] Z. Cao, L. Xuan, Q. Mu, L. Hu, Z. Peng, Y. Liu, L. Yao, Changchun Institute of Optics, Fine Mechanics and Physics (China)

$841514 \quad 1-m$ lightweight mirror design using genetic algorithm [8415-47]

H. Kihm, I. K. Moon, H.-S. Yang, Y.-W. Lee, Korea Research Institute of Standards and Science (Korea, Republic of)

841515 Study on numerical simulation of the dynamic impact effect for optical glass grinding with single grit [8415-62]

J. Chen, F. Zhang, Z. Hang, Z. Yong, J. Su, Harbin Institute of Technology (China)

841516 A novel method for calibrating the image distortion of the interferometer [8415-34] F. Yan, Institute of Optics and Electronics (China) and Graduate School of the Chinese Academy of Sciences (China); B. Fan, X. Hou, F. Wu, Institute of Optics and Electronics (China)

841517 Coating the 2-m level primary mirror with protected aluminum [8415-8]

W. Pei, H. Liu, Institute of Optics and Electronics (China); W. Du, Institute of Optics and Electronics (China) and Graduate School of the Chinese Academy of Sciences (China)

841518 Hyperspectral target detection based on improved automatic morphological endmember extraction method [8415-41]

X. Sun, Graduate Univ. of the Chinese Academy of Sciences (China) and Institute of Optics and Electronics (China); J. Cai, Z. XU, J. Zhang, Institute of Optics and Electronics (China)

841519 Study of gray image pseudo-color processing algorithms [8415-48]

J. Hu, Institute of Optics and Electronics (China) and Graduate School of the Chinese Academy of Sciences (China); X. Peng, Z. Xu, Institute of Optics and Electronics (China)

$84151 \mathrm{~A} \quad$ Fabrication of $1.8 \mathrm{~m}$ standard spherical mirror [8415-59]

J. Yu, S. Shen, J. Pan, Y. Mao, Y. MU, Nanjing Astronomical Instrument Research Ctr. (China) and Graduate School of the Chinese Academy of Sciences (China); M. Hu, Nanjing Astronomical Instrument Co. Ltd. (China)

8415 1B Analysis of deforming a 1.5-m ultrathin spherical mirror into an off-axis parabola [8415-3] C. Zeng, J. Yu, P. Guo, Soochow Univ. (China)

$84151 \mathrm{C}$ Optical testing of $\Phi 340 \mathrm{~mm} \mathrm{F/1.3} \mathrm{aspheric} \mathrm{surface} \mathrm{[8415-57]}$

J. Ren, P. Guo, Soochow Univ. (China)

8415 1D Research on reflective optical telescope system's wavefront aberration compensation method [8415-63]

X. Duan, Xi'an Institute of Optics and Precision Mechanics (China) 
$8415 \mathrm{IE}$ Theoretical and experimental study on the active support for thin mirror [8415-61]

Y. WU, Y. Zhang, F. WU, Institute of Optics and Electronics (China)

$84151 \mathrm{~F}$ Optical design of satellite laser communication integrative transceiver [8415-24]

Y. Cheng, X. Fan, G. Zou, P. Yan, K. Liu, Xi'an Institute of Optics and Precision Mechanics (China)

$84151 \mathrm{G}$ Study on large aperture SiC mirror technology [8415-44]

K. Gai, Beijing Polytechnic College (China)

Author Index 


\title{
Symposium Committee
}

\author{
Honorary Chair
}

Bingkun Zhou, Chinese Optical Society (China)

Symposium General Chair

Liwei Zhou, Beijing Optical Society (China)

Symposium General Cochairs

Jianlin Cao, Ministry of Science and Technology of China

Hiroki Kuwano, Nano Center of Tohoku University (Japan)

Yudong Zhang, Institute of Optics and Electronics (China)

Fritz Klocke, Fraunhofer Institute for Production Technology (Germany)

Wenhan Jiang, Institute of Optics and Electronics (China)

Jianzhong Xu, Chinese Academy of Sciences Institute of Engineering Thermophysics (China)

Ying Zhang, Xiamen University (China)

Xipeng Xu, Huaqiao University (China)

International Academic Committee

Wenhan Jiang, Chair, Chinese Academy of Engineering (China)

Liwei Zhou, Chinese Academy of Engineering (China) and Beijing Institute of Technology (China)

Jianzhong Xu, Institute of Engineering Thermophysics (China)

Xiangdi Lin, Chinese Academy of Engineering (China)

Pan Junhua, Chinese Academy of Engineering (China) and Soochow University (China)

Hiroki Kuwano, Tohoku University (Japan)

Fritz Klocke, Fraunhofer Institute for Production Technology (Germany)

James R. Torley, University of Colorado (United States)

Yoshiharu Namba, Chubu University (Japan)

James H. Burge, University of Arizona (United States)

Myung K. Cho, National Optical Astronomy Observatory

(United States)

Jose M. Sasian, University of Arizona (United States) 
Organizing Committee

Yudong Zhang, Cochair, IOE, CAS

Jinghua Cao, Cochair, Deputy Secretary for International Cooperation, CAS (China)

Libin Xiang, Cochair, Academy of Optoelectronics (China)

Anand Asundi, Cochair, Singapore Institute of Optics and Photonics (China)

Guoqiang Ni, Cochair, Chinese Optical Society (China)

Chenxu Wu, Cochair, Xiamen University (China)

Yadong Jiang, Cochair, University of Electronic Science and Technology (China)

Jiaxian Wang, Cochair, Huaqiao University (China)

Zhifeng Wang, Cochair, Institute of Electrical Engineering (China)

Lin Wang, Cochair, Optics and Optoelectronics Industry Society of China (China)

Program Committee

Xiangdi Lin, Chair, Chinese Academy of Engineering (China)

Yang Hu, Cochair, IOE, CAS (China)

Yuwen Qing, Cochair, Natural Science Foundation of China (China)

Haodong Yu, Cochair, Changchun University of Science and Technology (China)

Yoshiharu Namba, Cochair, Chubu University (Japan)

Myung K. Cho, Cochair, National Optical Astronomy Observatory (United States)

Secretariat General of the Symposium

Li Yang, Committee of Optical Manufacturing Technology (China) Jinxue Wang, SPIE

Session Chairs

Session 1-1 Fan Wu

Session 2-1 Qiming Xin

Session 3-1 Shangming Wen

Session 4-1 Xuefeng Liu

Session 5-1 Lei Zhang

Session 6-1 Rongzhu Zhang

Session 8-1 Tingwen Xing

Session 1-2 Bin Fan

Session 2-2 Rongzhu Zhang
Session 3-2 Sandy To

Session 4-2 Yanqiu Li

Session 5-2 Hui Lin

Session 7-1 Shangming Wen

Session 8-2 Tingwen Xing

Session 2-3 Qiming Xin

Session 3-3 Shangming Wen

Session 5-3 Zhu Ma 


\section{Introduction}

The 6th International Symposium on Advanced Optical Manufacturing and Testing Technology (AOMATT) was held 26-29 April 2012 at the Xiamen International Conference Center, Xiamen, China.

AOMATT 2012 was kicked off on April 26 with a formal opening ceremony. The ceremony started with the introduction of VIP guests, symposium chairs, and conference chairs, followed by opening speeches by Prof. Liwei Zhou, AOMATT 2012 Symposium Chairman, Prof. Bin XU, Vice President of IOE, sponsor of AOMATT2012, and Dr. Phil Stahl, Vice President of SPIE, technical cosponsor of AOMATT2012. Plenary sessions started immediately after the conclusion of the opening ceremony. There were a total of 10 plenary presentations: Dr. H. Philip Stahl, 2012 SPIE Vice President and NASA Marshall Space Flight Center (USA); Prof. Hiroki Kuwano, 2012 President of Japanese Mechanics Society and Director of Micro/Nano Center, Tohoku University (Japan); Dr. Fritz Klocke, President of Fraunhofer Institute for Production Technology IPT (Germany); Dr. James Burge, Professor of Optical Sciences and Astronomy at the University of Arizona (USA); Dr. Eric Ruch, SAGEM (France); Dr. Tilmann Heil, Director of System Engineering, Carl Zeiss SMT GmbH (Germany); Prof. W. B. Lee, Professor of Manufacturing Engineering and Director of Advanced Technology Manufacturing Research Centre, Hong Kong Polytechnic University; Dr Fengzhou Fang, Professor of Precision Measurement Technology and Instruments at Tianjin University (China); Prof. Shengyi Li, Professor of Mechatronics and Automation at the National University of Defense Technology (China). More than 1,000 people attended the opening ceremony and full-day plenary sessions.

More than 1,000 abstracts were submitted to AOMATT2012, and from these about 500 oral and poster papers were selected. Oral papers were presented in 8 parallel conferences on April 27 and 28. An all-symposium poster session was held in the afternoon of April 28. All of the parallel conference sessions and the poster session were well attended. Authors and attendees had active discussions and exchange of ideas throughout the symposium. Many papers presented cuttingedge research and development work in optical design, manufacturing, and testing. The success of AOMATT2012 continued the tradition of focus and excellence of this biannual international topical symposium in China.

We would like to express our sincere appreciation to COS - The Chinese Optical Society, IOE - Institute of Optics and Electronics, Chinese Academy of Sciences, and SPIE for sponsoring and supporting AOMATT2012. We want to thank all authors and participants for their contributions to the symposium and sharing their research with colleagues around the world. The 7th AOMATT is planned for 2014. 
We look forward to seeing everyone at AOMATT2014. Please watch for the Call for Papers and symposium announcements on SPIE and IOE web sites.

Li Yang

Jinxue Wang

Secretary General, AOMATT 20102

Proc. of SPIE Vol. $8415841501-12$

Downloaded From: https://www.spiedigitallibrary.org/conference-proceedings-of-spie on 26 Apr 2023 Terms of Use: https://www.spiedigitallibrary.org/terms-of-use 


\section{AOMATT 2012 SPONSORS}

Sponsored by

COS-The Chinese Optical Society (China)

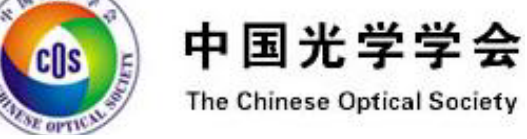

IOE-The Institute of Optics and Electronics, CAS (China)

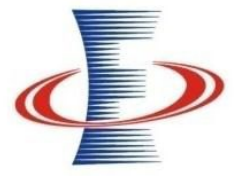

中国科学院光电技术研究所

THE INSTITUTE OF OPTICS AND ELECTRONICS

THE CHINESE ACADEMY OF SCIENCES

Technical Cosponsor

SPIE

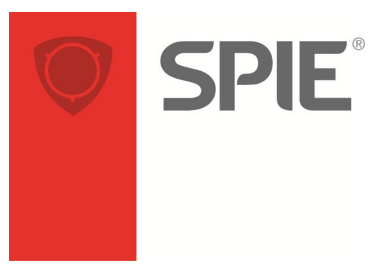

Supporting Organizations

Ministry of Science and Technology of China

Chinese Academy of Sciences

National Natural Science Foundation of China

\section{Cooperating Organizations}

Micro/Nano Science and Tech. Committee, Japan Society of Mechanical

Engineering • Application Optical Society of Germany • Optics and Photonics

Society of Singapore - Optoelectronic Industry Association of China • The Optical Society of Sichuan Province of China - State Key Laboratory of Optical

Technologies for Microfabrication, IOE, CAS - Key Laboratory on Adaptive Optics, IOE, CAS • National Univ. of Defense Tech. (China) • Univ. of Electronic Science and Tech. of China - Sichuan Univ. (China) - Xiamen University (China) • Huaqiao Univ. (China) • Hong Kong Polytechnic Univ. (Hong Kong China) • Harbin Inst. of Tech. (China) - Changchun Inst. of Optics, Fine Mechanics and Physics, CAS Changchun Univ. of Science and Tech. (China) • Beijing Inst. of Tech. (China) Univ. of Shanghai for Science \& Tech. (China) - Nanjing Univ. of Science and Tech. (China) • Inst. of Electrical Engineering, CAS 
Proc. of SPIE Vol. $8415841501-14$

Downloaded From: https://www.spiedigitallibrary.org/conference-proceedings-of-spie on 26 Apr 2023 Terms of Use: https://www.spiedigitallibrary.org/terms-of-use 